\title{
Impact of Stability Ball Sitting on Stroke Volume, Oxygen Content Difference, and Heart Rate During Arm Ergometry
}

\author{
Charles Rex Christopher Marks", Cecelia Goulette \\ Department of Human Movement Sciences, Exercise Science Program, Oakland University, Rochester, USA
}

Email address:

marks@oakland.edu (C. R. C. Marks)

${ }^{*}$ Corresponding author

To cite this article:

Charles Rex Christopher Marks, Cecelia Goulette. Impact of Stability Ball Sitting on Stroke Volume, Oxygen Content Difference, and Heart Rate During Arm Ergometry. American Journal of Sports Science. Vol. 6, No. 1, 2018, pp. 26-31. doi: 10.11648/j.ajss.20180601.15

Received: November 15, 2017; Accepted: December 15, 2017; Published: March 14, 2018

\begin{abstract}
The purpose of this study was to determine the contributions that heart rate (HR), stroke volume (SV), and oxygen content difference $\left(\mathrm{CdO}_{2}\right)$ make to the elevated oxygen consumption $\left(\mathrm{VO}_{2}\right)$ due to stability ball (SB) sitting when compared to chair (C) sitting during arm ergometry. Methods: Rest and two stages of exercise were conducted twice, once on a stability ball and once on a chair (order randomized) during aerobic arm cranking. $\mathrm{VO}_{2}$, cardiac output, and HR, were measured at the end of rest and each stage of exercise. $\mathrm{SV}$ and $\mathrm{CdO}_{2}$ were calculated from measured parameters. Results: Repeated Measures ANOVA demonstrated that SB was significantly higher than $\mathrm{C}$ by $4 \%$ to $12 \%$ for $\mathrm{VO}_{2}(\mathrm{P}<.001)$ and $2 \%$ to $4 \%$ for $\mathrm{HR}$ (P $=.016)$. SB was non-significantly higher by $0.5 \%$ to $2.1 \%$ for SV $(\mathrm{P}=.358)$. In addition, there was a significant interaction with increasing differences between $\mathrm{SB}$ and $\mathrm{C}(1 \%$ to $6 \%)$ with higher intensities for $\mathrm{CdO}_{2}(\mathrm{P}=.014)$. It was concluded that oxygen content differences make a larger contribution to the difference between SB and $\mathrm{C}$ at the higher intensity. The patterns of change with exercise for heart rate, stroke volume, and oxygen content difference were similar between SB and C.
\end{abstract}

Keywords: Swiss Ball, Aerobic Arm Exercise, Cardiac Output, Oxygen Extraction

\section{Introduction}

Most studies involving the stability ball have examined it for use with callisthenic like exercises to in an effort to enhance core muscular activation $[1,2]$ or to replace chair sitting at a desk to possibly prevent low back pain $[3,4]$. There have been only two published papers that have explored the use of the stability ball with aerobic exercise $[5,6]$. These studies reported arm ergometry outcomes while sitting on a stability ball (SB) during sub-maximal (8) and peak aerobic exercise (9). Though oxygen consumptions $\left(\mathrm{VO}_{2}\right)$ were significantly higher $(8 \%$ to $12 \%)$ on SB than when sitting on a chair $(\mathrm{C})$, heart rates (HR) were only significantly higher $(2 \%$ to $3 \%)$ at peak and near peak $\mathrm{VO}_{2}(8,9)$. Those studies demonstrated that one could elevate metabolism during aerobic arm exercise without affecting the exercise prescription based on heart rate. This could be useful fitness and rehabilitation centers. A pilot study has found similar responses in cardiac rehabilitation participants [7]. For wider use of an
SB during arm ergometry, especially for cardiac patients, further studies on the cardiovascular responses should be undertaken. When solving Fick's equation [8] for $\mathrm{VO}_{2}(=$ $\mathrm{HR} * \mathrm{SV} * \mathrm{CdO}_{2}$ ) and considering the heart rate response in both of those past studies, it is implicit that stroke volume (SV), oxygen content difference $\left(\mathrm{CdO}_{2}\right)$ or both were increased during submaximal exercise with SB. SV has been shown to plateau at moderate intensities of exercise $[9,10]$ and would indicate that $\mathrm{CdO} 2$ should be the primary source of oxygen at higher intensities. However, SV was also shown to plateau at higher intensities [11] and this would indicate that SV could still contribute to the higher oxygen requirements of SB. To date no studies have been conducted examining these parameters during arm ergometry while sitting on a SB. Therefore, the purpose of this study was to determine if SB sitting, when compared to C sitting, affects SV, HR, $\mathrm{CdO}_{2}$, and $\mathrm{VO}_{2}$ during arm ergometry. 


\section{Methods}

\subsection{Participants}

Following IRB approval, apparently healthy male and female young adults (18 to 39 years) who were at least moderately active (e.g. walk 30 minutes 3 days/week) were recruited. Using $\alpha=.05,80 \%$ power, 5\% difference, and standard deviation values from past studies, at least 25 participants were needed to be recruited.

\subsection{Practice Day}

Following an orientation and informed consent, sitting SB and $\mathrm{C}$ shoulder heights from the floor were measured with a stadiometer. SB and $\mathrm{C}$ seating heights were adjusted to be within $2 \mathrm{~cm}$ of each other by placing a wooden platform under the lower sitting mode. This was done to maintain the same arm height for both seating modes in relation to the ergometer crank. Practice trials were then conducted to familiarize the participant to the equipment and exercise protocol. In addition, this practice also allowed the investigators to determine the appropriate power outputs and associated $\mathrm{CO}_{2}$ concentrations for the rebreathing bag. Practice consisted of rest and two stages of exercise while sitting on a chair. The $1^{\text {st }}$ Stage power output was initially set at 10 to $15 \mathrm{~W}$ then adjusted until HR increased from rest by 20 to $40 \mathrm{~b} / \mathrm{min}$. The power output that achieved this increase in heart rate was noted. This took four to five minutes to accomplish. Immediately following the $1^{\text {st }}$ stage of exercise, the $2^{\text {nd }}$ stage of exercise was increased initially by another 10 to $15 \mathrm{~W}$ and adjusted again until HR increased by another 20 to $40 \mathrm{~b} / \mathrm{min}$ above the $1^{\text {st }}$ stage's HR. The power output that achieved this increase in heart rate was noted. This took four to five minutes to accomplish. Following practice on the arm ergometer while sitting on the chair, the participant then practiced exercising while sitting on a stability ball with two three minute stages at the power outputs determined while sitting on the chair. The power outputs were set to be the same for both the stability ball and chair. Practice included all monitoring equipment (see Figure 1).

\subsection{Testing Day}

Following the practice day (48 hours later), two trials (48 hours between) with rest and two stages of arm exercise were done: one trial on SB and the other trial on $\mathrm{C}$ (order randomized), Participants were asked to crank at 50 revolutions per minute (rpm) and could see the displayed during the arm cycling along with hearing a metronome set to assist with maintaining a constant rpm. An investigator regularly observed the rpms. $\mathrm{VO}_{2}, \mathrm{VCO}_{2}$, Cardiac Output (Q), and HR were measured after 3 minutes of rest or exercise. Q was estimated from the $\mathrm{CO}_{2}$ rebreathing technique [8]. Q was calculated using Fick's equation with $\mathrm{CO}_{2}$ as the indicator gas: $\mathrm{Q}=\mathrm{VCO}_{2} /\left(\mathrm{CvCO}_{2}-\mathrm{CaCO}_{2}\right)$. Systemic arterial $\mathrm{CO}_{2}$ content $\left(\mathrm{CaCO}_{2}\right)$ was estimated from systemic arterial $\mathrm{PCO}_{2}$ using 10-20 seconds of normal breathing end-tidal $\mathrm{CO}_{2}$ and Jones et al.'s equation [12].
Systemic mixed venous $\mathrm{CO}_{2}$ content $\left(\mathrm{CvCO}_{2}\right)$ was estimated from systemic mixed venous $\mathrm{PCO}_{2}$ by Collier's rebreathing method using 5-10 seconds of rebreathing $10.5 \%$ to $12.5 \%$ $\mathrm{CO}_{2}$ with the balance in $\mathrm{O}_{2}$ and Jones et al.'s equation [13]. Pressure values were converted to content by using McHardy-Jones's equation [14]. The rebreathing was done twice unless the difference between the two Qs was $>0.5$ $\mathrm{L} / \mathrm{min}$, in which case a third measurement was done and then averaged.

\subsection{Equipment}

A Monark Arm Ergometer (881 E) calibrated with a $2 \mathrm{~kg}$ weight was used for the two stages of exercise. A $65 \mathrm{~cm}$ diameter Stability Ball (BodyFit) was inflated to manufacture's recommendation and used during the SB condition. An ordinary chair with back support but no arm rests with the seat height $45 \mathrm{~cm}$ from the floor was used for the C condition. A "TrueOne" metabolic cart (Parvomed) was used for the $\mathrm{VO}_{2}, \mathrm{VCO}_{2}$, and rebreathing measurements. The cart's pulmonary ventilation meter was calibrated with a $3 \mathrm{~L}$ syringe while the expired gas analyzers were calibrated with $4 \% \mathrm{CO}_{2}$ and $16 \% \mathrm{O}_{2}$ before each testing session.

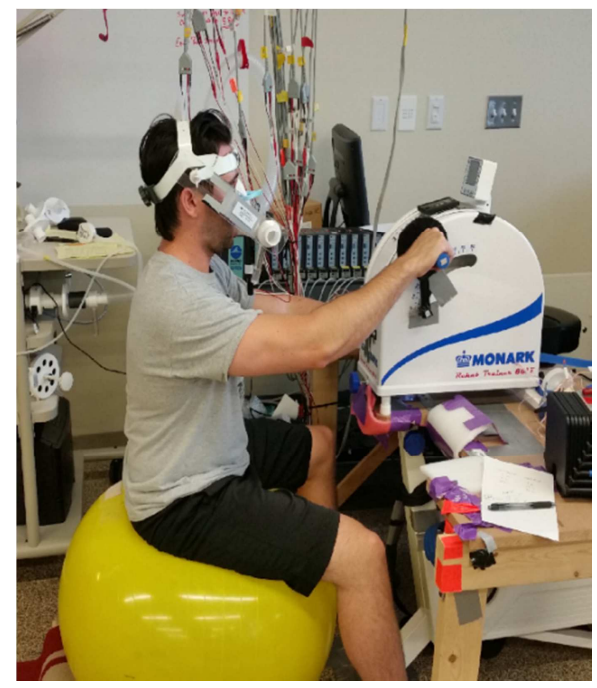

Figure 1. Exercise Ergometer Station.

\subsection{Calculations and Statistical Analysis}

Stroke Volume was calculated as SV $=\mathrm{Q} / \mathrm{HR}$. Oxygen content difference was calculated as

$$
\mathrm{CdO}_{2}=\mathrm{VO}_{2} / \mathrm{Q} \text {. }
$$

A 2 (sitting mode) x 3 (stage of activity) ANOVA for repeated measures with $\alpha \leq .05$ was done using SPSS (11.0) for each dependent variable.

\section{Results}

Eighteen female $(22 \pm 3 \mathrm{yrs}, 61.5 \pm 6.5 \mathrm{~kg})$ and eleven male $(23 \pm 2$ yrs, $77.3 \pm 7.1 \mathrm{~kg})$ participants were studied. Mean \pm SD Power Output was $19 \pm 7 \mathrm{~W}$ for stage 1 and $32 \pm$ $10 \mathrm{~W}$ for stage 2 . SB sitting was significantly higher than $\bar{C}$ 
sitting by $4 \%$ to $12 \%$ for $\mathrm{VO}_{2}(\mathrm{P}<.001)$ and $2 \%$ to $4 \%$ for HR $(\mathrm{P}=.016)$. SB was non-significantly higher by $0.5 \%$ to $2.1 \%$ for SV $(\mathrm{P}=.358)$. In addition, there was a significant interaction with increasing differences between $\mathrm{SB}$ and $\mathrm{C}$
$(1 \%$ to $6 \%)$ with higher intensities for $\mathrm{CdO}_{2}(\mathrm{P}=.014)$. Figures two through five display the $\mathrm{VO}_{2}, \mathrm{HR}, \mathrm{SV}$, and $\mathrm{CdO}_{2}$ results.

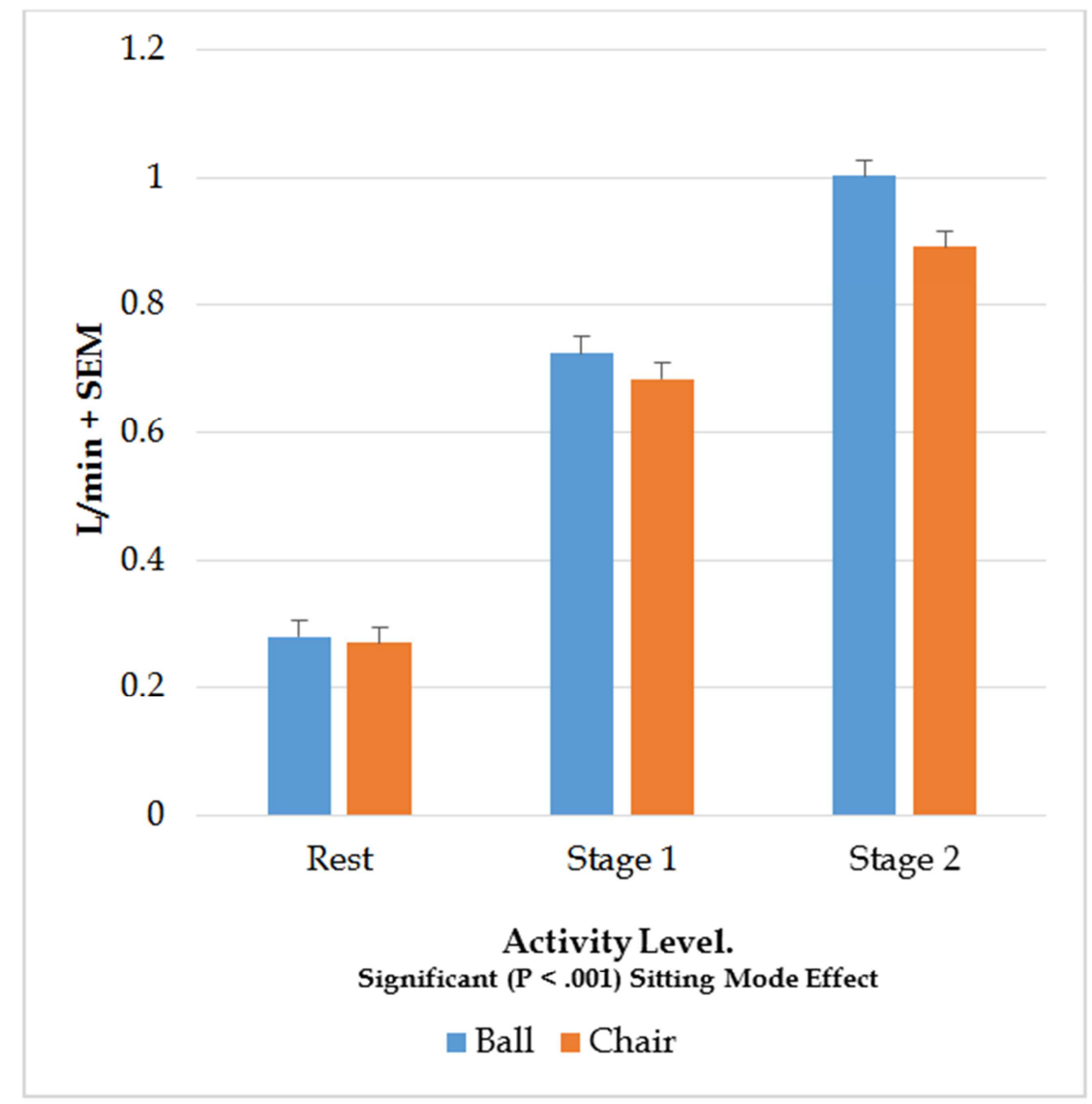

Figure 2. Impact of Stability Ball Sitting on VO2 During Arm Ergometry.

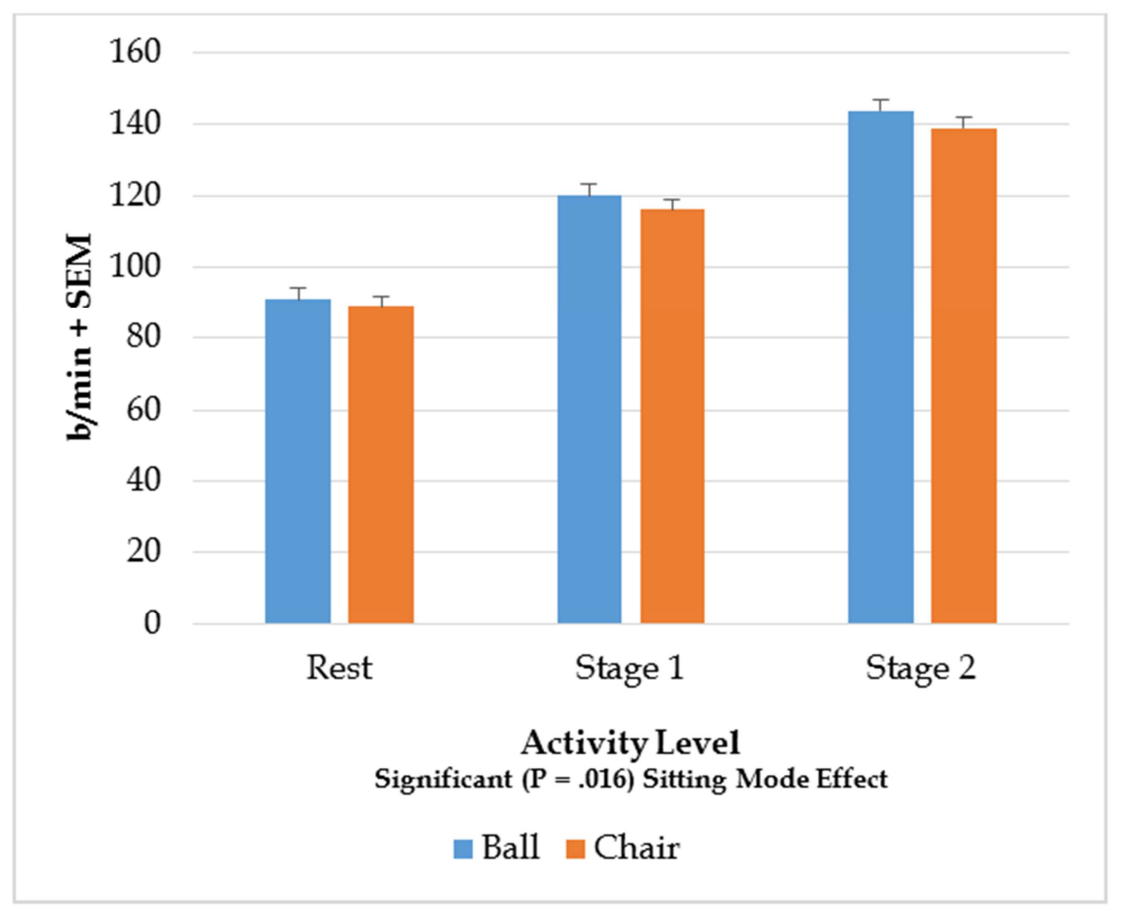

Figure 3. Impact of Stability Ball Sitting on Heart Rate During Arm Ergometry. 


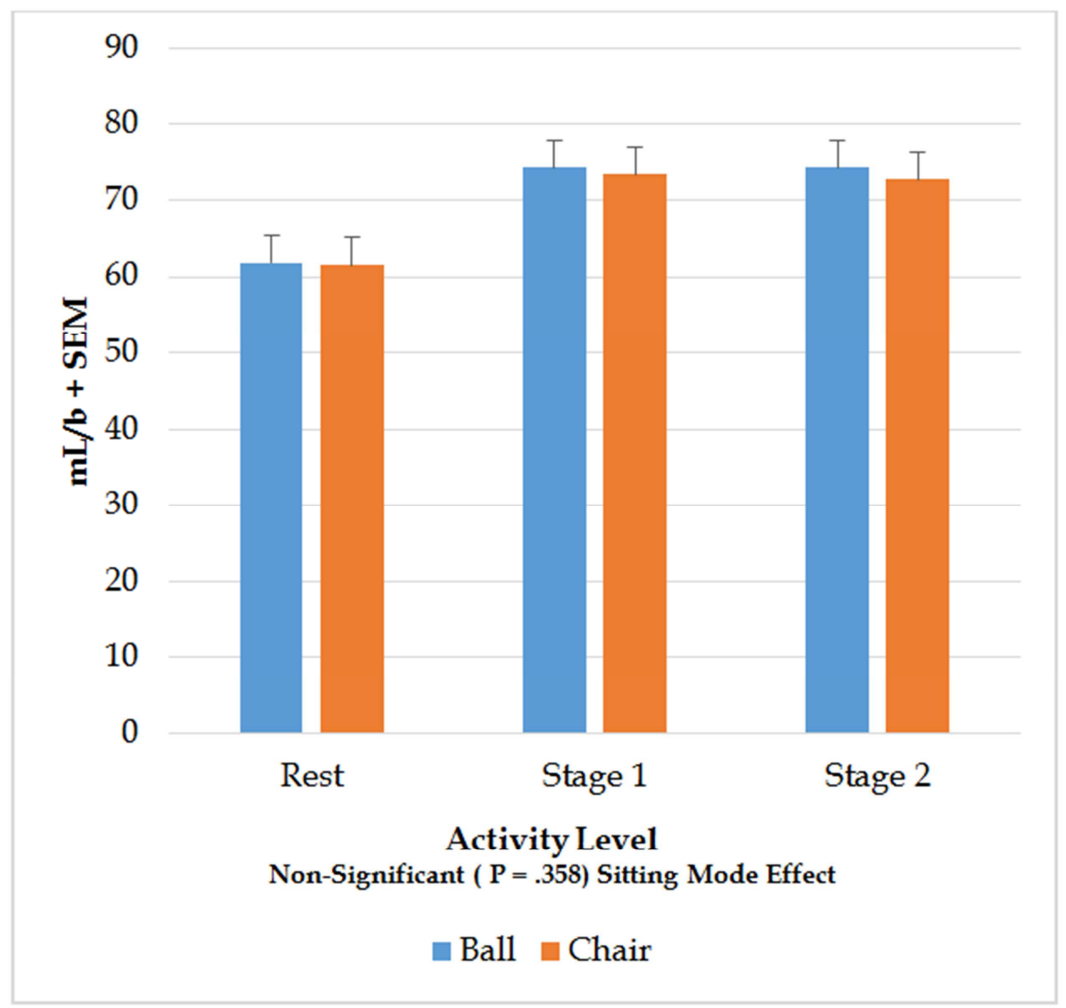

Figure 4. Impact of Stability Ball Sitting on Stroke Volume During Arm Ergometry.

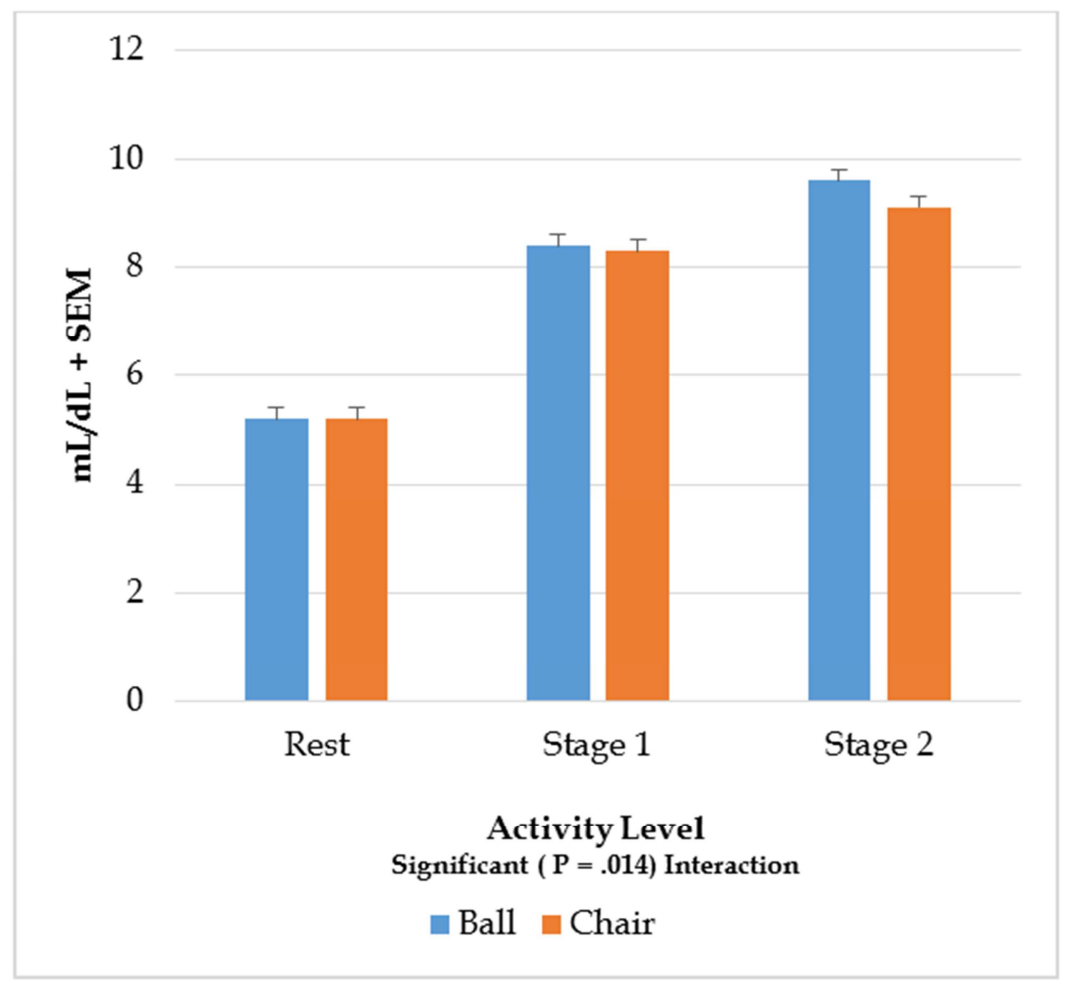

Figure 5. Impact of Stability Ball Sitting on Oxygen Content Difference During Arm Ergometry.

\section{Discussion}

Consistent with the only past studies [5, 6] using a SB during aerobic exercise, the current study elevated $\mathrm{VO}_{2}$; however, unlike the past studies the current one had small but significantly higher submaximal heart rates with SB. The percentage differences in this study were at the same level as the significant high intensity HRs in the prior study [6]. Sitting height probably did not cause the difference since the 
earlier studies and the current one adjusted the sitting heights between the $\mathrm{SB}$ and $\mathrm{C}$ conditions to be the same. However, the SB in the current study was different from the other two studies: Prior studies' SB had a much stiffer material while the current study's SB was more elastic. This may indicate that the characteristics of SB can affect the exercise response, however, there are no studies that have examined this among different stability balls.

The current study was the first to examine $\mathrm{SV}$ and $\mathrm{CdO}_{2}$ during aerobic arm exercise while sitting on a stability ball. This study was consistent with past studies that demonstrated a plateauing of SV in upright exercise at moderate intensities of arm exercise [9, 10, 15]. In addition, the current study's $\mathrm{SB}$ and $\mathrm{C}$ HRs and $\mathrm{CdO}_{2} \mathrm{~S}$ increased with increased intensity and were consistent with other reports on graded aerobic arm exercise $[9,10,11]$. It appeared that $\mathrm{HR}$ and $\mathrm{CdO}_{2}$ contribute to the higher $\mathrm{O}_{2}$ supply for the $\mathrm{SB}$ condition initially. However, $\mathrm{CdO}_{2}$ took on a greater portion for the second stage of exercise especially for SB. This is consistent with a plateauing of SV with moderate exercise.

Past studies found SVs to be lower during arm exercise when compared to leg exercise when done in the upright position $[9,10,11,16]$ and about the same during supine exercise [10]. Those findings indicated that the level of active muscle mass and body positon affect SV. The level of active muscle mass was probably greater during SB in the current study since it was demonstrated that SB sitting increased leg muscle activity in the only study to report electromyography data with SB sitting during arm ergometry [5]. However, the increased muscle activity on SB may not have been enough to affect SV. The body position was not markedly affected by SB since both sitting modes were upright exercise and sitting height had been controlled for. In addition, hip angle and upper body joint angles were probably not affected by SB though the lower legs may have been slightly extended and abducted on SB in the only study to examine this [5]. Since there was probably greater leg muscle activity with SB (1) but SV was not significantly affected in the current study, it was possible that greater oxygen extraction in the leg muscles occurred, that was consistent with the higher $\mathrm{CdO}_{2}$. Oxygen content difference was reported to be lower during arm exercise when compared to leg exercise $[10,16,17]$ and indicated greater potential to tap into if other muscles become activated. The participants in the current study were at least moderately active so a number of them could have had an increased capacity to extract oxygen since exercise training was shown to increase arm $\mathrm{CdO}_{2}[14,16]$. The current study's results indicate that the stability ball elevates metabolism during arm ergometry without making unusual changes in stroke volume, heart rate, and oxygen content difference. This suggests that exercise programs that incorporate arm ergometry can use a stability ball to enhance energy expenditure without altering the exercise target heart rate. Though it would need to be confirmed, these results may indicate that using a stability ball during arm ergometry in the rehabilitation setting could be useful too.

The current study did not vary the type of stability ball nor chair. The study also limited the participants to adults that were under 40 years of age and at least moderately active. The impact that the stability ball had during arm ergometry was limited to acute responses and no studies have been done to determine any training effects.

\section{Conclusion}

This is the first study demonstrating that replacing chair sitting with a stability ball can elevate cardiorespiratory parameters especially oxygen content difference during arm ergometry. The pattern of the Heart Rate, Stroke Volume, and $\mathrm{O}_{2}$ extraction responses to submaximal exercise were similar for both the stability ball and chair siting though the stability ball had higher $\mathrm{VO} 2$ and $\mathrm{O}_{2}$ extraction.

\section{References}

[1] Duncan, M. Muscle activity of the upper and lower rectus abdominis during exercises performed on and off a swiss ball. J Bodywork Move Ther 13: 364-367, 2009.

[2] Sternlicht, E, S Rugg, LL Fuji, KF Tomomitsu, MM Seki. Electromyographic comparison of a stability ball crunch with traditional crunch. J Strength Cond Res 21(2): 506-509, 2007.

[3] Gregory DE, NM Dunk, JP Callaghan. Stability ball versus office chair: Comparison of muscle activation and lumbar spine posture during prolonged sitting. Hum Factors 48 (1): 142-153, 2006.

[4] McGill, SM, NS Kavcic, E Harvey. Sitting on a chair or an exercise ball: Various perspectives to guide decision making. Clin Biomech 21: 353-360, 2006.

[5] Marks, CRC; Hylland, KE; Terrell, J. Stability Ball Sitting Versus Chair Sitting During Sub-maximal Arm Ergometry. Int J Exerc Sci 5(1):16-25, 2012.

[6] Marks, CRC; Dupuie, L; Patros, J. Stability Ball Sitting Elevates Peak Arm Ergometry Oxygen Consumption and Heart Rate. Int J Exerc Sci 5(4): 360-366, 2012.

[7] Marks CRC, K Bronsteen, B Hibner, JK Ehrman, D Kerrigan, SJ Keteyian. Cardiorespiratory Responses of Cardiac Rehabilitation Participants to Stability Ball Sitting during Arm Ergometry Med Sci Sports Exerc. 2013;45(5 Suppl):S646.

[8] Marks, C, V Katch, A Rocchini, R Beekman, A. Rosenthal. Validity and Reliability of Cardiac Output by $\mathrm{CO}_{2}$ Rebreathing: A Review. Sports Medicine. 2:432-446, 1985.

[9] Keteyian, SJ, CRC Marks, AB Levine, T Kataoka, F Fedel, TB Levine. Cardiovascular responses to submaximal arm and leg exercise in cardiac transplant patients. Med Sci Sports Exerc 26(4):420-424, 1994.

[10] Stenberg, J, P Astrand, B Ekblom, J Royce, B Saltin. Hemodynamic respose to work with different muscle groups, sitting and supine. J Appl Physiol 22(1): 61-70, 1967.

[11] Calbert, JAL, J Gonzalez-Alonse, JW Helge, H Sondergaard, $\mathrm{T}$ Munch-Anderson, B Saltin, $\mathrm{R}$ Boushel. Central and peripheral hemodynamics in exercising humans: Leg vs arm exercise. Scand J Med Sci Sports 25(s4):144-157, 2015. 
[12] Jones, NL, DG Robertson, JW Kane. Differences between end-tidal and arterial $\mathrm{PCO} 2$ in exercise. $J$ Appl Phys 47(5):954-960, 1979.

[13] Jones, NL, DG Robertson, JW Kane, JM Campell. Effect of $\mathrm{PCO} 2$ on alveolar-arterial $\mathrm{PCO} 2$ difference during rebreathing. $J$ Appl Phys 32(6):782-787, 1972.

[14] Perterson, DH, DA Cunningham. Comparison of methods to calculate cardiac output using the $\mathrm{CO} 2$ rebreathing. Eur $J$ Appl Phys 35: 223-230, 1976.
[15] Clausen, JP. Circulatory adjustments to dynamic exercise and effect of physical training in normal subjects and in patients with coronary artery disease. Prog Card Dis 18:459-495, 1976.

[16] Clausen, JP, K Klausen, B Rasmussen, J Trap-Jensen. Central and peripheral circulatory changes after training of the arms or leg. Am J Physiol 225(3): 675-682, 1973.

[17] Pendergast, DR. Cardiovascular, respiratory, and metabolic responses to upper body exercise. Med Sci Sports Exerc 21(5S): S121-S125, 1989. 